\title{
Embodied Cognition: Laying the Foundation for Early Language and Literacy Learning
}

\author{
HETTY ROESSINGH \\ University of Calgary \\ MICHELLE BENCE \\ University of Calgary
}

\begin{abstract}
For children, hands are the critical conduit for learning the world and constructing mental models of its size and shape. Such embodied cognition (EC) is mediated through language in the social environment. In this paper we review the literature and develop the conceptual underpinnings for a framework for play-based pedagogy that integrates sensorimotor, cognitive, and linguistic systems that lay the foundations for early literacy experiences expected in the kindergarten and Grade 1 year. We provide suggestions for incorporating games and tasks in a play-based program that will promote EC.
\end{abstract}

Keywords

embodied cognition; play-based pedagogy; early literacy

\section{Introduction}

Mounting research evidence suggests today's youngsters arrive at school insufficiently prepared for the early and more formal demands of their first educational experiences. The Early Development Instrument (EDI) is a pan-Canadian initiative that measures children's ability to meet age-appropriate developmental expectations in five general domains: physical health and well-being, social competence, emotional maturity, language and cognitive development, and communication skills and general knowledge (Janus \& Offord, 2007; Janus \& Reid-Westoby, 2016; Offord \& Janus, 2000). Data indicate $27 \%$ of Canada's five-year-olds are vulnerable on at least one of the five domains assessed. The detrimental, distal impact of these indicators on children's early literacy development, especially written literacy, at the end of Grade 2 is only beginning to be understood-largely through research evolving from the neurosciences (Dinehart \& Manfra, 2013; James \& Atwood, 2009).

Achievement data in early literacy learning (Alberta Education, 2014; Shonkoff \& Phillips, 2000, 2007) indicate two concerning trends: overall, general slippage in early literacy development outcomes and, secondly, a persistent and growing achievement gap over time in the shift to academic literacy development among linguistically vulnerable populations of children including those raised in poverty or of language minority background. Emergent research findings suggest the etiological underpinnings to these trends may be found in children's control over fine motor skills and their influence on language learning as these are the major drivers of literacy development over time (Suggate \& Stoeger, 2014). 
The catalyst for our interest in this topic relates to an early literacy action research project completed during 2012-2016 with gifted learners in Grade 2 (Roessingh \& Bence, 2017). Our findings pointed to the need for upstream interventions, as early as the kindergarten year, to bolster neuromotor control and to reset the trajectory for the exigencies of early literacy production including drawing, printing, and spelling.

The goal of this article is to advance a conceptual framework that will inform the design of purposeful play-based pedagogy in kindergarten and to provide suggestions for how the model might be implemented in the context of a play-based program. We draw on the three research domains of sensorimotor, cognitive, and linguistic development. These domains interact within the over-arching dimension of embodied cognition as they are facilitating the foundational mind-body-brain connections made possible by creating the neurocircuitry or neuro-pathways that underpin literacy.

We begin by providing further background information on early childhood and literacy development to set the context for the reader, and we define the construct of play. We elaborate on the role of embodied cognition and its crucial role in later literacy learning. We then review the relevant research from the three domains identified above working toward our conceptual framework for play-based pedagogy. We provide suggestions for activities and tasks that might be embedded in an early childhood kindergarten program that will promote the foundational concepts and skills for early literacy to come in the immediate years ahead.

\section{Inside the "Black Box": Why Are Our Young Children Unprepared for Literacy Learning?}

Speculation as to the root causes of children's lack of readiness for kindergarten across socio-economic status backgrounds are varied and multi-faceted. Increased exposure to digital devices and screen time (Ravichandran, France de Bravo, \& Beauport, 2018); the complexity and changing nature of the family structure; the stresses of home and workplace demands; the changing demographic landscape across North America reflecting rapidly increasing linguistic and cultural diversity; diminished opportunities for exploratory physical play with clay, blocks, puzzles, crayons, scissors and paper, (Long, Bergeron, Leicht Doyle, \& Gordon, 2006; Westervelt, 2015); and, crucially, insufficient outdoor play may all have detrimental consequences for children's linguistic, social, and physical development (Williams et al., 2008).

Indeed, many scholars of play research report the paucity of any kind of play in the kindergarten setting. Wilson, a neurologist recognized for his seminal works in explaining the phylogenic origins and evolutionary development of the hand (1998) and its connection to young children's perceptual, motor, and cognitive growth, foresaw and forewarned the negative consequences of the physically and sensory impoverished environments in which many children are raised (1999). Wilson cautioned against the increasing preoccupation with technology and digital devices among young children, noting this would diminish time allocated to physical activity and exploration. He emphasized the crucial need for children to learn the world through their hands, as the hands are the primary channel through which the brain tunes itself to the world in which we live, work, and play. Children cannot bypass or shortcut this step in abstracting concept information relevant to early literacy learning by gazing passively at visually mediated simulations on a screen. Time 
for the work of childhood is a necessity in Wilson's view, not a luxury, and it cannot be rushed.

Nevertheless, there appears to be pressure to introduce a more academic curriculum at ever earlier stages of children's involvement with the school system where kindergarten is "the new Grade 1" (Bodrova \& Leong, 2015; Bassok, Latham, \& Rorem, 2016; Pyle \& Danniels, 2017). A growing body of research, however, indicates that an early overemphasis on decontextualized literacy readiness skills, such as phonics instruction, provides no longitudinal advantage in literacy achievement (Suggate, Shaughency, \& Reese, 2013). Children whose entry into formal schooling is delayed, such as those in Finland (Walker, 2015) who are afforded learning opportunities in the interim through an array of playful engagements with language, materials and physical exploration in realworld contexts, readily close the literacy gap, scoring among the top-ranking countries globally on measures of literacy and numeracy.

There has been a recent resurgence of interest in children's written literacy development, perhaps as a consequence of slipping achievement in early literacy outcomes (e.g. Alberta Education, 2014), as reflected in the reintroduction of both manuscript and cursive hand by some jurisdictions. In our own work with gifted young learners (Roessingh \& Bence, 2017), we observed a concerning gap among many Grade 2 students between their exceptional measured vocabulary knowledge and reading comprehension outcomes, and their ability to mobilize lexical resources in the service of making and conveying meaning through print mode. We attribute this gap to difficulties in the domain of physical/neuromotor readiness visible in the distinct belaboured look of their printing efforts (Figure 1). Note, for example, the inconsistency in shape and size of letter formation, and the difficulty maintaining space and alignment of print.

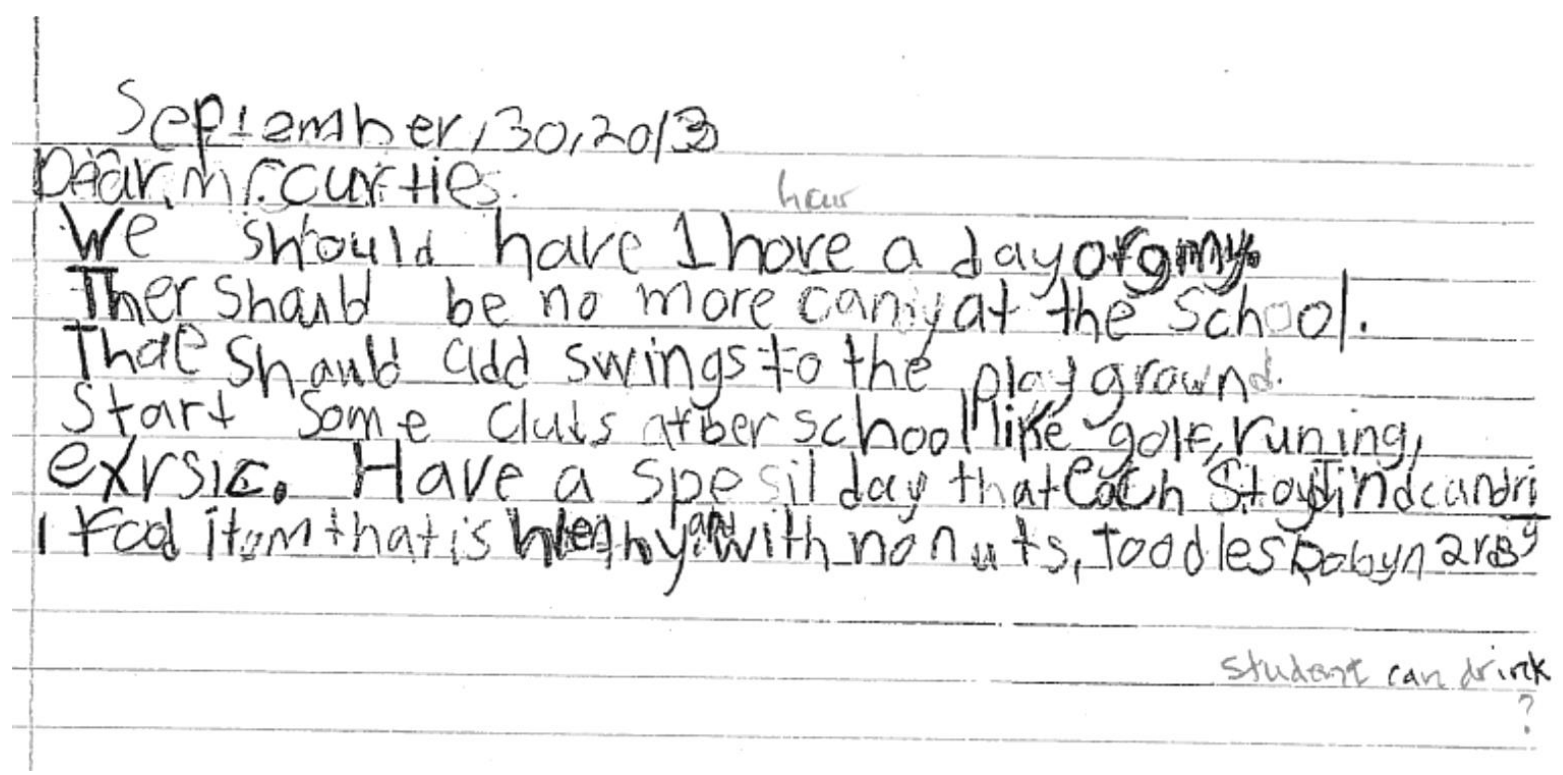

Figure 1. Belaboured Printing

While explicit, instructed support produced tangible impact on both the quality and quantity of most students' writing in Grade 2, in our view this intervention was insufficient to remediate the neuromotor demands of early literacy learning, and consequently the 
overall achievement outcomes for written literacy remained well below what we anticipated for gifted young learners. Figure 2 illustrates improvement in the student's printing efforts after participating in the Handwriting Without Tears (Olsen, 2003) program. The student's printing is immediately and readily legible, due to improved consistency in shape, size, and spacing. As noted previously, we identify the need for upstream interventions beginning in kindergarten to address this concern.

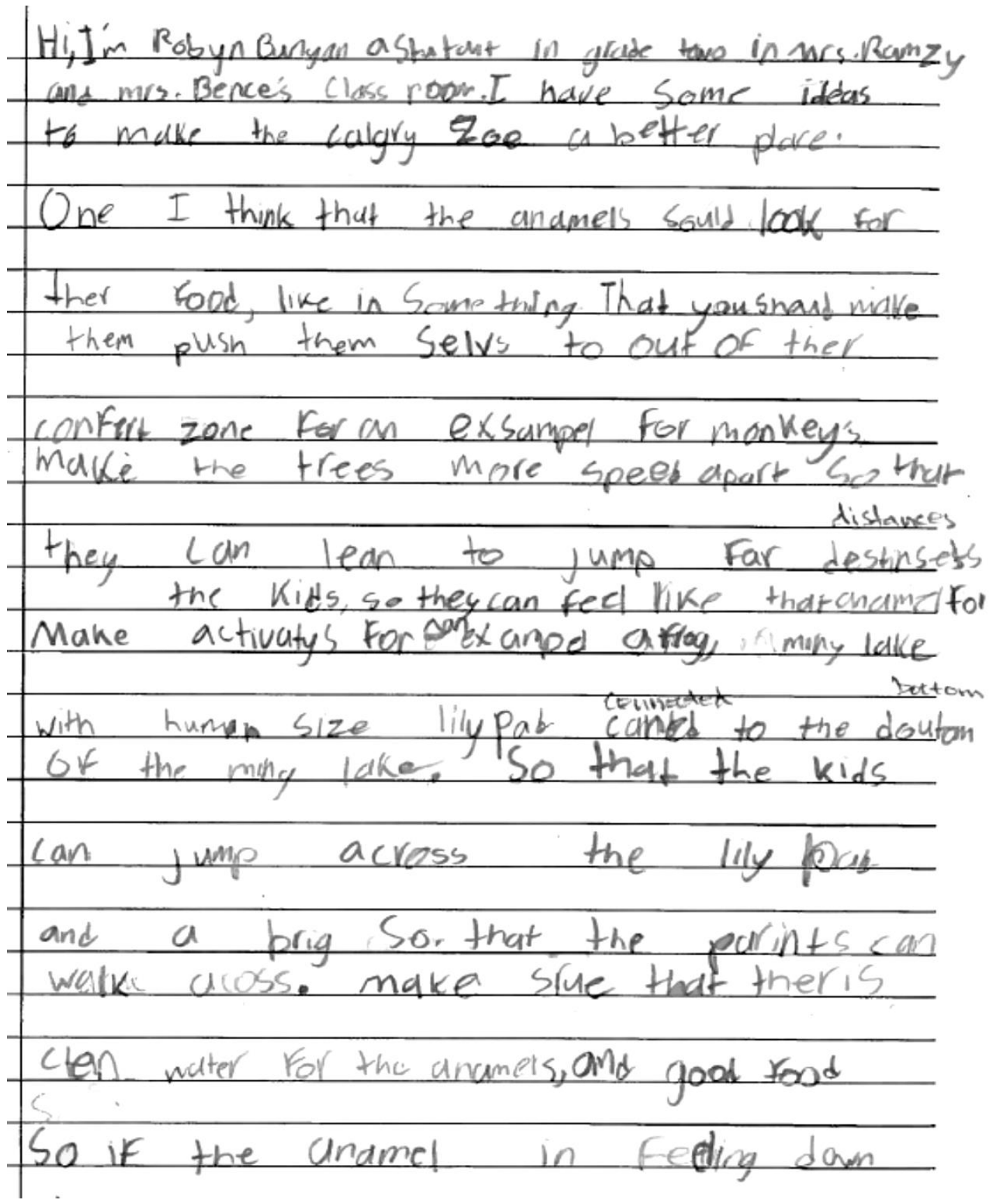




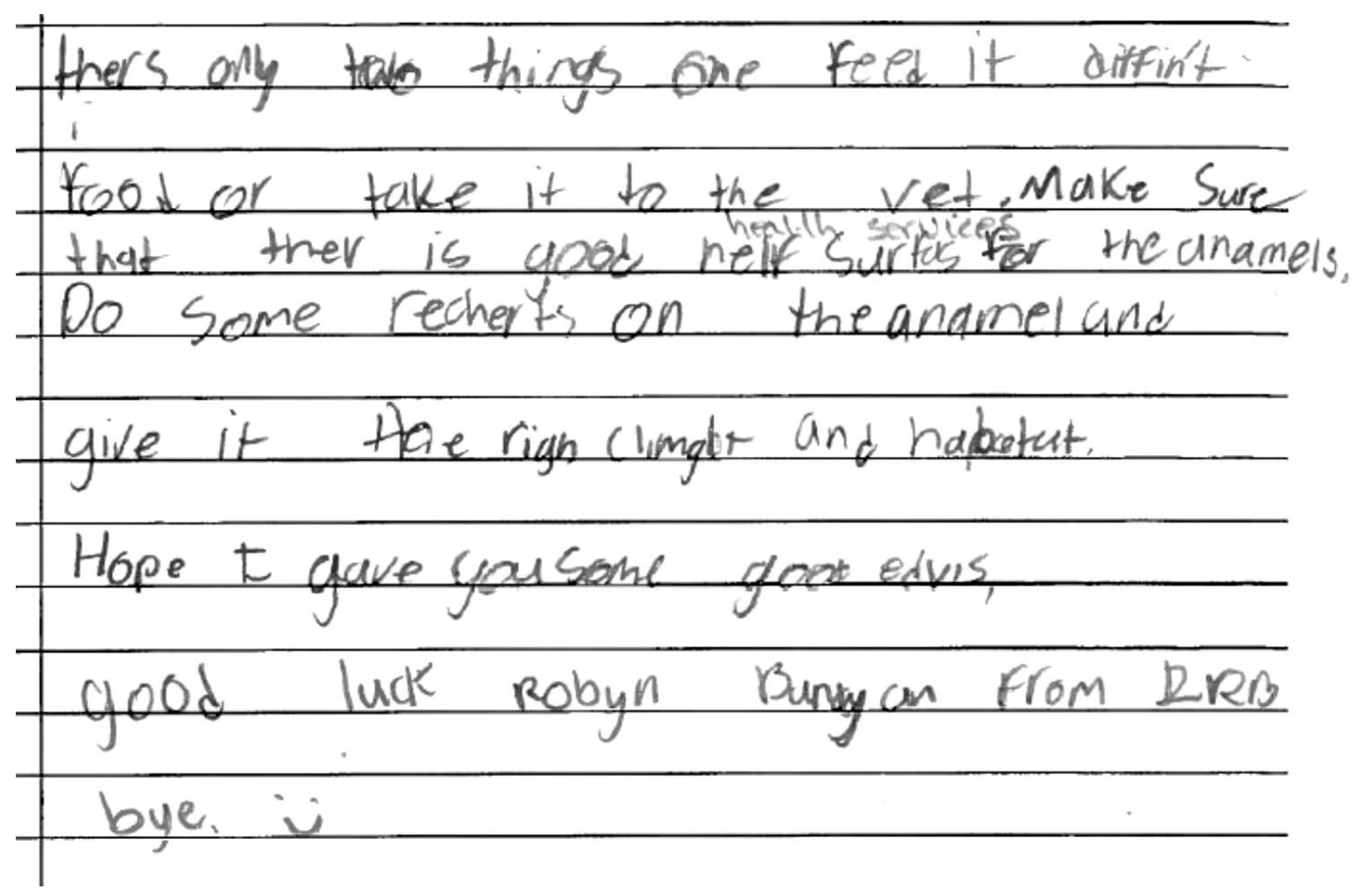

Figure 2.

Research in early literacy development is overwhelmingly focused on reading rather than writing, perhaps based on the assumption that they will unfold simultaneously, given they share analogous underlying processes and cognitive skills. Relevant research in the area of neuromotor development and the connection to literacy learning, particularly printing, is sparse. Further, a review of the literature on play-based learning is heavily focused on creative and imaginative/ pretend play, discovery and inquiry, and sociodramatic play as these have a consequence for social and cognitive development (Vygotsky, 1933; Bodrova \& Leong, 2015). The play-literacy interface (e.g. phonemic awareness, phonics connections) may be influenced by exposure through pretend play to telephone messages and lists, for example (Roskos \& Christie, 2001, 2011). However, the crucial body-mind-brain connection required for learning to print, predicated on sensorimotor engagement and central to the construct of EC is largely overlooked in the extant literature. This is the niche we seek to occupy with our work.

\section{Emergent Understandings from the Neurosciences: Embodied Cognition}

Embodied cognition (EC) underscores the connection between sensorimotor engagement and young children's ability (and, indeed, older learners as well) to learn the world by internalizing haptic information from direct experience and manipulation of objects and materials to linguistic mapping, thus advancing their cognitive growth (Ionescu \& Vasc, 2014; Kiefer \& Trumpp, 2012).

EC draws on Piagetian notions of the centrality of active sensorimotor involvement in connection to cognitive development as it unfolds through an endless series of windows of opportunity, or sensitive periods, that open and close over time (Beilin \& Fireman, 1999; 
Ginsberg \& Opper, 1969; Page, 1959). The second half of Grade 1 has been identified as the optimal window of opportunity for children to mobilize neuromotor, cognitive, and linguistic resources in the service of representing their thoughts through print mode (Roberts, Derkach-Ferguson, Siever, \& Rose, 2014). This assumes, however, that children have been afforded the prerequisite opportunities, largely through play, making them "ready" for this shift to literacy. Concepts of shape, size, space, and pattern are important in making this shift (James \& Atwood 2009; Rawlins, 2015). Many would argue that "play is the work" of childhood - the occupational predecessor of school (Lillard, 2013).

A related field of research endeavor, physical literacy, makes the important link between the child's awareness of body in space (proprioception) to movement and action with objects and tools, for example, and is predicated on an array of fine and gross motor skills which, in turn, have a distinct impact on the ability to identify and efficiently print letters. Rule and Stewart (2002) report that children who are given opportunities to play with real-life objects such as tweezers develop control over the fine motor skills (e.g. pincer grip) required for early print literacy development (Bergman, 2013; Greutman, 2010). Fine motor skills that aid small muscle movements such as pencil grip, pencil control, and independent finger movement have all been identified as precursors to writing skills (Keifer, 2015; Lamme, 1979). Moreover, a distal effect is observed between early control over fine motor processes and later academic success.

A growing body of research establishes the connection between fine motor skills and cognition (Piek, 2008; Wellsby \& Pexman, 2014) as well as with language (Borghi, Flumini, Cimatti, Marocco, \& Scorolli, 2011). In an elegantly designed study, Suggate and Stoeger (2014) investigated the links between vocabulary items with strong body object interaction (BOI), vocabulary items for general knowledge on the Peabody Picture Vocabulary Test, and four tasks measuring fine motor (FM) dexterity and handedness among five-year-old children. BOI items are words for which action or tactile involvement leads directly to meaning making, such as the word "belt." They report correlations between FM and knowledge of vocabulary items with BOI as well as with general vocabulary knowledge.

A related domain of research, embodied communication, makes the link between using gestures from an early stage in infancy to their efforts to communicate; infants gesture to make meaning before the capacity to do so solely through language is fully realized. The early use of gestures is a harbinger of later vocabulary production. Further, the use of gestures not only promotes cognition (Dewar, 2017), it aids retrieval and memory of vocabulary over time (Cook, Yip, \& Goldin-Meadow, 2010; Demire \& Goldin-Meadow, 2016). These researchers underscore the idea that while gestures and embodied communication in early life support language development, play increasingly relies on language skills as do almost all endeavors in life. EC remains important throughout life whether in the performing arts; sports; crafts and hobbies such as knitting; daily life skills such as driving a car; or in the educational tasks of schooling where demonstrations, simulations and the like are an important step to automatizing skills and linguistic information concomitantly.

Helen Keller (1880 - 1968) left a rich legacy of insights related to how language, BOI, gesture, and sign language interacted to construct meaning in her mind, beginning with that moment at the water fountain where her teacher, Annie Sullivan, at last broke through the silence and darkness of her young pupil's life: 
As the cool stream gushed over one hand she spelled into the other the word water, first slowly, then rapidly. I stood still, my whole attention fixed upon the motions of her fingers. Suddenly I felt a misty consciousness as of something forgotten--a thrill of returning thought; and somehow the mystery of language was revealed to me. I knew then that 'w-a-t-e-r' meant the wonderful cool something that was flowing over my hand. That living word awakened my soul, gave it light, hope, joy, set it free! (Keller, 1903).

Just as our first upright-walking hominid ancestors staked everything on the use of their hands millions of years ago - picking and grabbing; launching, throwing and catching; caressing and stroking; and using tools as a prosthesis for getting things done-Annie Sullivan intuitively understood this would be the only pathway to the brain for young Helen. The moment is poignantly recorded in an Academy Award winning performance and is a reminder of the inextricable body-mind-brain connection (Coe \& Penn, 1962).

\section{Defining the Construct of "Play"}

Play is a broad construct that eludes any single definition and lacks both conceptual clarity and consensus among play theorists, the research community, classroom practitioners, and parents of young children (Fisher, Hirsh-Pasek, Golinkiff, \& Gryfe, 2008; Gilbert, Harte, \& Patrick, 2011; International Play Association, 2014; National Association for the Education of Young children, 2014; Roskos \& Christie, 2011). The thread that appears to unite the various foci on play-based learning includes:

- pleasure or amusement, entertainment/fun;

- simple, sheer and pure joy for children;

- play is its own reward and is self-reinforcing.

Play activities may be child (or teacher) initiated and open-ended to promote inquiry (Pyle \& Danniels, 2017) and discovery through pretend/creative/imaginative play; or structured/ organized/goal oriented/purposeful, and more reflective of "real world" situations through role plays and sociodrama. Play may be engaged in as a solitary activity or in groups of all configurations and sizes.

We position various types of play by way of a matrix organized along two continua illustrated in Figure 3. The vertical axis represents the shift from child to adult initiated or directed play; the horizontal axis represents play environments from less to increasingly more structured settings. We utilize this matrix in conceptualizing our framework for a play-based pedagogy for kindergarteners. 


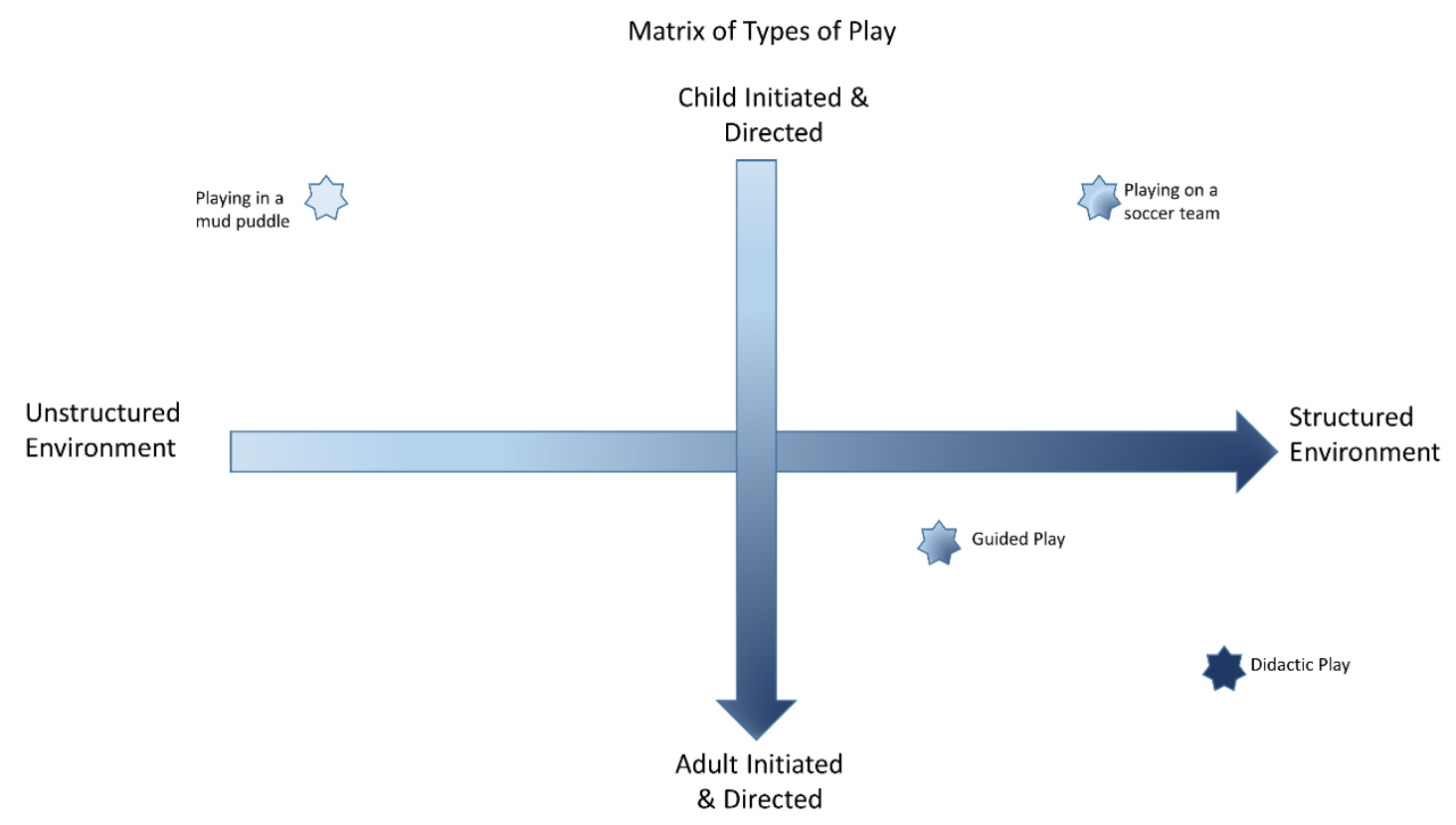

Figure 3. Matrix of play activities (Roessingh \& Bence, 2017)

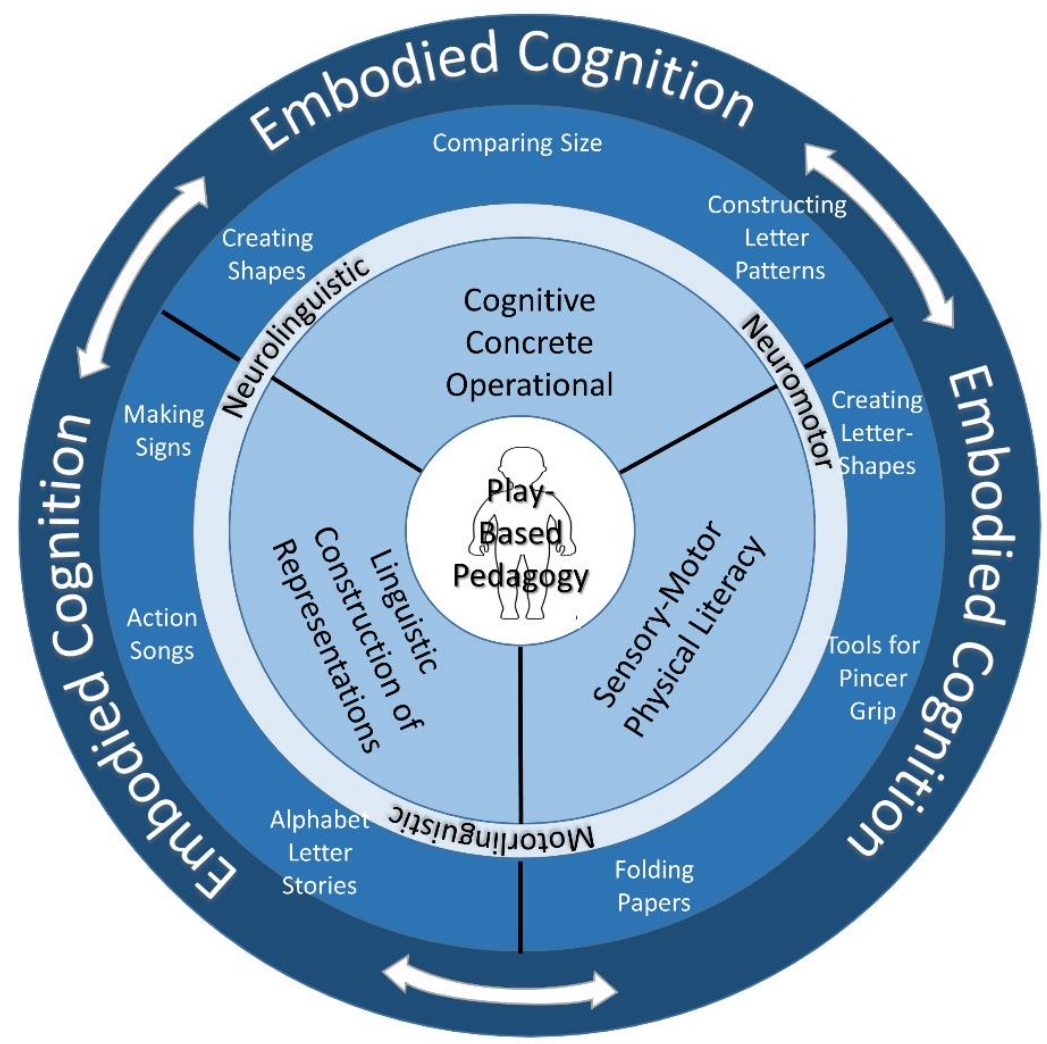

Figure 4. Conceptual Framework for Play-Based Pedagogy 
We place the child at the center of our framework, interacting with our designed, purposeful play tasks and activities with real objects and materials in real time, thus making the crucial connections between cognition, sensorimotor and language development, and embodied cognition. The framework is sufficiently flexible to guide the design of a playbased program for diverse learner profiles depending on individual student needs and the degree of explicitness called for. Recall Figure 3, where we advised a position in the quadrant that is more structured and teacher initiated/directed. There are instances in our program design where teacher direction will be important, for example, in teaching children the correct way to develop a pincer grip (Greutman, 2010). Follow-up tasks and activities will be more open and flexible to child choice and child-directed play.

Gifted children, for example, are often characterized by an asynchronous pattern of development, with the cognitive and language domains well in advance of the neuromotor/physical domain. Thus, in the design of our play-based program, it will be crucial to attend to the distinct gap between language and conceptualizations about the real world, and the neuromotor requirements of engaging with and manipulating tools and equipment that are part and parcel of reinforcing the body-mind-brain nexus.

English language learners, or, children who speak a language other than English at home, are a growing demographic in school populations. While many of these children have distinct strengths in the neuromotor domain (Roessingh, 2017), as well as in phonemic awareness and phonics understandings, many of them need structured support in vocabulary development from an early age. And there are sure to be other children with various learning needs represented by way of the three domains or dimensions included in Figure 3 above.

By placing the child at the center of the play-based framework, we encourage early childhood practitioners to glean insights into individual learning needs through an array of play-based "tasks" that might reveal these needs. Increasingly, it would seem that a balanced approach that promotes play founded on all three dimensions will be needed. In the section that follows we suggest activities, tasks, and the use of materials that will support such a program.

\section{Implementing the Framework in the Context of a Play-Based Program}

Inspired by Montessori's ideas about the prepared environment and the role of materials (Montessori, 1914), as much as possible we intend our materials to consist of simple, everyday household objects and materials (i.e. realia) that are inexpensive to purchase and put together for our young students (Rule \& Stewart, 2002). Buttons and beads (loose parts), nuts and bolts (things that fit together), blocks, clay, pick up sticks/chopsticks, clothes pegs, string; paper, scissors, and glue sticks; pencils, crayons, markers and paper; tweezers, tongs and other utensils, and various containers comprise our materials tool kit.

We want to encourage children to imagine everyday objects readily available in most homes as objects for discovery, learning, creative, imaginative, and social play. This is the essence of the emerging maker culture (Dougherty, n.d.). Further, children might be involved firsthand in making materials. A current kids' craze is making and playing with slime, easily made with just a few ingredients that affords finger workouts as kids knead, stretch, role, and shape their slime or simply play with it as a relaxation activity by making it a stress ball. 
Below is a series of suggestions for games and tasks from the three dimensions highlighted in the framework presented in Figure 4. While teachers and parents are likely to be familiar with these already, the key to including them here is the theoretical underpinnings to the broader construct of embodied cognition that may not be apparent and understood. We underscore this point in our concluding comments and thoughts.

1. Shared storybook reading. Books such as Rosie's Walk (Hutchins, 1971) promote "languaging" around directional words, and imagining and drawing objects in space. Henry's Map (Elliott, 2013) and Lucy in the city: A story about developing spatial thinking skills (Dillemuth, 2015) bridge to learning activities that promote spatial reasoning through finger tracing and drawing maps. A new release, Carson Crosses Canada (Bailey \& Reich, 2017) also encourages skills related to mapping. These are important precursors to both literacy and numeracy concepts. In addition, children learn geography concepts through such storybooks.

2. Loose parts play. Sorting and categorizing small objects such as buttons and beads encourages fine motor development and the connection to mental concepts of shape, size, space, and patterns. These concepts are foundational for literacy learning (i.e. alphabet recognition, printing, and spelling). Children need an enormous amount of exposure, direct experiences, and time with an array of attribute pieces to internalize these concepts. A tray of "loose parts" (for each child) allows children to experiment and push the boundaries by creating more complex patterns, from early work on sorting and categorizing, which should be relatively easy for them.

3. Playing with plasticine. Kneading, molding, and manipulating plasticine gives little fingers a great workout! Children might challenge themselves to shape the ball of plasticine so that it floats in water. They delight in trying various shapes, with those "ahead of the curve" figuring out that weight and shape both play a role in whether the object will float. At age five, an important concept relates to conservation of mass and object permanency.

4. Arts and crafts projects. Paper folding (origami), stringing, beading, cutting, and finger painting promote fine motor skills, develop physical literacy, and reinforce the neural pathways needed for later printing and written communication.

5. Music, songs, and nursery rhymes. These activities expose children to the structure, pattern, and movement that underlies literacy concepts. These activities promote phonemic awareness in a naturally engaging way, with the additional benefit of introducing cultural capital for a growing demographic of young learners who are unlikely to be exposed to this information at home. Adding finger plays, gestures, and dance to these activities enhances sensorimotor (large and fine) skills, proprioception and the link to cognition. 
6. Cooperative play. Sociodramatic play centers such as post office, grocery store, or restaurants, introduce and allow for the practice of the "scripts" for daily life, and the opportunity to role-play them. Realia for the post office can include paper, envelops, writing tools, and stamps. Tasks can involve recognizing addresses and directions, and sorting by letters or numbers.

7. Outdoor physical and exploratory play. Ball handling (throwing/ catching/ kicking), exploring playground equipment (hanging, climbing), and playing simple team games promote physical literacy. Paired with the use of equipment such as rackets, bats, and sticks, these games promote physical literacy, and, in particular, body awareness in space. Games and friendly competition further foster the development of social skills through the give and take of team play.

Our thoughts for planning guided play and its place in the kindergarten program represents only a portion of how children will spend their time. The overall program will benefit from a certain amount of free play (child-initiated and unstructured), imaginative and creative play, and the judicious use of technology.

\section{Conclusion}

On the face of it, parents and teachers have always understood the importance of play and afforded opportunities through play for the physical, cognitive and linguistic, social and emotional growth of children. Marzollo and Lloyd's (1972) book, Learning Through Play, is as relevant today as it was 45 years ago. It is as if we are rediscovering what we have long known about ourselves: humankind is by nature a tinkerer, an explorer, an adventurer, a creator, a thinker, a maker, and a do-it-your-self-er driven by an insatiable innate sense of curiosity, wonder, physical and mental challenge, and the need to know. The contemporary maker movement is a return to creating, rather than consuming, across a wide range of domains in a social, participatory environment that values physical exploration and effort.

Sixty years ago, city kids in Alberta played endlessly outdoors in mixed groups whether in loosely, spontaneously organized teams or individually on the neighborhood playground on the ubiquitous slides, swings, monkey bars, and teeter-totters. In late fall, the boards for an ice rink would appear through volunteer community effort and winter months drifted into spring through hour upon hour of outdoor play on the ice. Some communities even had night lights and intermittent music playing over a loudspeaker to encourage free-skating into the evening. Family time in the evenings often involved playing card games, board games, reading and constructing with blocks, and playing with simple implements such as pick-up sticks. Farm kids could spend countless hours taking things apart and putting them back together, "fixing" things, refurbishing an old car, in short, satisfying the human need for physical interaction with the material world in a quest to know, to be creative, and to be productive.

Handcrafts such as knitting, and simple hobbies such as keeping a penny or rock collection soaked up many hours while promoting fine motor skills, and learning about the objects in the collections. A Dinky Toy collection allowed for hours of imaginative play, and tasks such as sorting the tiny vehicles into trucks, cars, emergency transport, farm, and construction equipment. All of this was part of the intuitive rhythm of family life and 
childhood no one really questioned. It is as if time is turning back upon itself with the reemergence of interest in making jewelry, clothing, furniture, wine, food of all kinds, perfumes, bath products, and knowledge sharing through the affordances of social media.

The value and importance of physical exploratory play, sensorimotor engagement and processing, and early language, literacy and numeracy development and their connection to embodied cognition is only beginning to emerge as a focus of research endeavor. Underpinning embodied cognition is the importance of fine motor development as this affords the hands (and the child the sense of agency) direct contact and the ability to handle and manipulate objects and tools that thus build the neurocircuitry to lay the body-mind-brain pathways and connections for both early (and later) language, literacy, and numeracy learning (Dinehart \& Manfra, 2013). The evolving research is being undertaken across a broad range of disciplines, mostly outside of the domain of education and is often not readily accessible to the classroom practitioner. Educational researchers must take and make what they can in transforming and applying the findings to classroom practices that teachers can adopt and adapt in building balanced play-based programs that will enhance children's early readiness in kindergarten for the upcoming demands of more formal literacy learning (Marcon, 2012).

It will be important, too, to make the connection to parents to inform them of their role in promoting the types of early childhood experiences we have outlined throughout this article. Shared storybook reading, for example, needs to begin in the earliest months of life; activities that help a toddler to gain control over finger movement begin in the first year of life. Waiting to intervene and reset the developmental trajectory upon entry into kindergarten at age five means losing precious, opportune moments to invite children to the "just right" play they need. As community engaged scholars, we also need to connect to the media. Recent newspaper articles on the benefits of play allude to the social, psychological, and creative aspects of play, and the importance of fresh air and interaction with other children on the playground (Fortney, 2017; Nieman, 2017). The importance of $\mathrm{EC}$ and the key role of developing fine motor skills is too frequently overlooked.

Various data indicate that our children are not as prepared as they need to be for their formal encounters with literacy learning that may have far-reaching consequences in their longitudinal academic outcomes that can be avoided with timely, appropriate interventions. In our view, it is the failure to understand the underpinnings of the importance of play that is the culprit.

Our pitch is simply for an informed understanding of the value of purposeful, guided play that positions our youngest learners to be better prepared for the literacy tasks that depend on cognitive, linguistic, and neuromotor development. The framework we advance is intended to be flexible in encouraging early childhood teachers to be more intentional in planning for play in the increasingly diverse contexts of the contemporary classroom.

\section{References}

Alberta Education (2014). Provincial Achievement Tests. Multi-year reports. Retrieved from https://education.alberta.ca/provincial-achievement-tests/patresults/everyone/pat-results/

Bailey, L., (2017). Carson crosses Canada. New York, NY: Tundra Books. 
Bassok, D., Latham, S., \& Rorem, A. (2016). Is kindergarten the new first grade? AERA Open, 1(4), 1-31.

Beilin, H., \& Fireman, G. (1999). The foundation of Piaget's theories: Mental and physical action. Advances in Child Development and Behavior, 27, 221-246.

Bergman, J. (2013). The human hand: Perfectly designed. Creation Research Society Quarterly, 50, 25-30.

Blake, B., \& Pope, T. (2008). Developmental psychology: Incorporating Piaget's and Vygotsky's theories in the classroom. Journal of Cross-Disciplinary Perspectives in Education, 1(1), 59-67.

Bodrova, E., \& Leong, D. (2015). Vygotskian and post-Vygotskian views on children's play. American Journal of Play, 7(3), 372-388.

Borghi, A., Flumini, A., Cimatti, F., Marocco, D., \& Scorolli, C. (2011). Manipulating objects and telling words: A study on concrete and abstract words acquisition. Frontiers of Psychology, 2(15).

Brown, C. G. (2010). Improving fine motor skills in young children: An intervention study. Educational Psychology in Practice, 26(3), 269-278.

Coe, F. (Producer), \& Penn, A. (Director). (1962). The Miracle Worker [Motion picture]. United States: Playfield Productions.

Cook, S., \& Tanenhaus, M. (2009). Embodied communication: Speakers' gestures affect listeners' actions. Cognition, 113 (1), 98-104.

Cook, S., Yip, T., \& Goldin-Meadow, S. (2010). Gesturing makes memories that last. Journal of Memory and Language, 63, 465-475.

Demir, O., \& Goldin-Meadow, S. (2016). Gesture's role in learning and processing language. In G. Hickok \& S. Small (Eds.), Neurobiology of Language (pp. 275283). Retrieved from http://www.sciencedirect.com/science/article/pii/B9780124077942000237

Dewar, G. (2017). The science of gestures: Why 'talking' with our hands can help children think and learn. Parenting Science. Retrieved from http://www.parentingscience.com/gestures.html

Dewey, J. (1938). Experience and education. New York, NY: Macmillan. Retrieved from https://en.wikipedia.org/wiki/Experience_and_Education_(book)

Dillemuth, J. (2015). Lucy in the city: A story about developing spatial thinking skills. Washington, DC: Maginatin Press.

Dinehart L., \& Manfra, L. (2013). Association between early fine motor development and later math and reading achievement in early elementary school. Early Education and Development, 24(2), 138-161.

Dougherty, D. (nd). The maker mindset. https://1lk.media.mit.edu/courses/readings/maker-mindset.pdf

Elliott, D. (2013). Henry's Map. New York, NY: Philomel Books.

Fisher, K., Hirsh-Pasek, K., Golinkoff, R., \& Gryfe, S. (2008). Conceptual split? Parents' and experts' perceptions of play in the 21st century. Journal of Applied Developmental Psychology, 29(4), 305-316.

Fortney, V. (2017, September 16). Experts in play discuss best ways for kids to develop while having fun. Calgary Herald, $p$. A6.

Gilbert, J., Harte, H., \& Patrick, C. (2011). Purposeful play leads to school readiness. Dimensions of Early Childhood, 39(1), 29-35. 
Ginsberg, H., \& Opper, S. (1969). Piaget's theory of intellectual development: An introduction. Englewood Cliffs, NJ: Prentice Hall, Inc.

Greutman, H. (2010, September 28). Typical pencil grasp development for writing. Growing Hands-On Kids. Retrieved from https://www.growinghandsonkids.com/pencil-grasp-development-for-writing.html

Grissmer, D., Grimm, K. J., Aiyer, S. M., Murrah, W. M., \& Steele, J. S. (2010). Fine motor skills and early comprehension of the world: Two new school readiness indicators. Developmental Psychology, 46(5), 1008-17.

Hutchins, P. (1971). Rosie's Walk. New York, NY: Aladdin Publishers.

Ionescu, T., \& Vasc, D. (2014). Embodied cognition: Challenges for psychology and education. Procedia: Social and Behavioral Sciences, 128, 275-280.

International Play Association (2014). Declaration of the importance of play. Retrieved from http://ipaworld.org/wp-content/uploads/2015/05/IPA_DeclarationFINAL.pdf

James, K., \& Atwood, T. (2009). The role of sensorimotor learning in the perception of letter-like forms: Tracking the causes of neural specialization for letters. Cognitive Neuropsychology, 26(1), 91-110.

Janus, M., \& Offord, D. (2007). Development and psychometric properties of the Early Development Instrument (EDI): A measure of children's school readiness. Canadian Journal of Behavioral Science, 39(1), 1-22.

Janus, M., \& Reid-Westoby, C. (2016). Monitoring development of all children: The Early Development Instrument. Early Childhood Matters, 125, 40-46.

Keifer, J. J. (2015). Handwriting and fine motor skill development in the kindergarten classroom. (Unpublished master's thesis). Texas Christian University, Texas.

Keller, H. (1903). The story of my life. New York, NY: Random House.

Kiefer, M., \& Trumpp, N. M. (2012). Embodiment theory and education: The foundations of cognition in perception and action. Trends in Neuroscience and Education, 1(1), 15-20.

Lyytinen, P., Laakso, M., Poikkeus, A., \& Rita, N. (1999). The development and predictive relations of play and language across the second year. Scandinavian Journal of Psychology, 40(3), 177-186.

Lamme, L. L. (1979). Handwriting: In an early childhood curriculum. Young Children, 35(1), 20-27.

Lillard, A.S. (2013). Playful learning and Montessori education. American Journal of Play, 5(2), 157-186.

Long, D., Bergeron, J., Leicht Doyle, S., \& Gordon, C. (2006). The relationship between frequency of participation in play activities and kindergarten readiness. Occupational Therapy in Health Care, 19(4), 23-42.

Marcon, R. A. (2012). The importance of balance in early childhood programs. In S. Suggate \& E. Reese (Eds.), Contemporary debates in child development and education (pp. 159-168). London: Routledge, Taylor \& Francis.

Marzollo, J. \& Lloyd, J. (1972). Learning through play. New York, NY: Harper Books.

Mason. J. (2016). Handwriting fluency and legibility. Intervention program for schools. Warwickshire County Council. https://www.swft.nhs.uk/application/files/2914/6158/0965/6_handwriting_fluency _and_legibility.pdf 
Montessori, M. (1965). Dr. Montessori's own handbook. New York, NY: Schocken Books. [Original work published 1914]. Retrieved from https://archive.org/details/drmontessorisow00montgoog

National Association for the Education of Young Children (2014, May). Defining and advocating for play. Young Children. Retrieved from: http://fliphtml5.com/hawo/meov/basic

National Research Council and Institute of Medicine (2000). From neurons to neighborhoods: The science of early childhood development. Committee on Integrating the Science of Early Childhood Development. J. Shonkoff \& D. Phillips, Eds. Board on Children, Youth, and Families, Commission on Behavioral and Social Sciences and Education. Washington, DC: National Academy Press.

Nieman, P. (2017, November 9). Children — and parents — need to make time to play. Calgary Herald, p. C5.

Offord, D., \& Janus, M. (2000). Early Development Instrument. [Measurement instrument]. Hamilton, ON: McMaster University. Retrieved from https://edi.offordcentre.com/

Olsen, J. (2003). Handwriting Without Tears. Cabin John, MD: Western Psychological Services.

Özçalışkan, S., \& Goldin-Meadow, S. (2005). Gesture is at the cutting edge of early language development. Cognition, 96(3), B101-B113.

Page, E. (1959). Haptic perception: A consideration of one of the investigations of Piaget and Inhehlder. Education Review, 11(2), 115-124.

Piasta, S., \& Wagnar, R. (2010). Developing early literacy skills: A meta-analysis of alphabet learning and instruction. Reading Research Quarterly, 45(1), 8-38.

Piek, J., Dawson, L., Smith, L. M. \& Gasson, N. (2008). Early fine and gross motor development on later motor and cognitive ability. Human Movement Science, 27(5), 668-681.

Pyle, A., \& Danniels, E. (2017). A continuum of play-based learning: The role of the teacher in play-based pedagogy and the fear of hijacking play. Early Education and Development, 28(3), 274-289.

Ravichandran, P., France de Bravo, B., \& Beauport, R. (2018). Young children and screen time. National Center for Health Research. Retrieved from http://www.center4research.org/young-children-screen-time-tv-computers-etc/

Rawlins, K. (2015). The relationship of gross motor acquisition to pre-academic success in a group of pre-school students enrolled in an early intervention program.

(Doctoral dissertation). Retrieved from https://www.researchgate.net/publication/281178077_The_Relationship_of_Gross _Motor_Acquisition_to_Preacademic_Success_in_a_Group_of_Preschool_Students_Enrolled_in_an_Early_I ntervention_Program

Roberts, G., Derkach-Ferguson, A., Siever, J., \& Rose, S. (2014). An examination of the effectiveness of Handwriting without tears ${ }^{\circledR}$ instruction. Journal of Occupational Therapy, 81(2), 102-113.

Roessingh, H. (2018). Unmasking the early language and literacy needs of ELLs: What K-3 practitioners need to know and do. BC TEAL Journal, 3(1), 22-36. 
Roessingh, H., \& Bence, M. (2017). Intervening in early written literacy development for gifted children in Grade 2: Insights from an action research project. Journal for the Education of the Gifted, 40(2), 168-196.

Roskos, K. A., \& Christie, J. F. (2001). Examining the play-literacy interface: A critical review and future directions. Journal of Early Childhood Literacy, 1(1), 59-89.

Roskos, K. A., \& Christie, J. F. (2011). The play-literacy nexus and the importance of evidence-based techniques in the classroom. American Journal of Play, 4(2): 204-24.

Rule, A., \& Stewart, R. (2002). Effects of practical life materials on kindergartners' fine motor skills. Early Childhood Education Journal, 30(1), 9-13.

Rushton, S., Juola-Rushton, A. \& Larkin, E. (2010). Neuroscience, play and early childhood education: Connections, implications and assessment. Early Childhood Education Journal, 37(5), 351-61.

Shonkoff, J. \& Phillips, D. (2007). The science of early childhood development: Closing the gap between what we know and what we do. (Research Report). National Scientific Council on the Developing Child. Retrieved from https://developingchild.harvard.edu/resources/the-science-of-early-childhooddevelopment-closing-the-gap-between-what-we-know-and-what-we-do/

Steiner, R. (2003). Education: An introductory reader. (n.p.): Rudolf Steiner Press.

Suggate, S., Schaughency, E., \& Reese, E. (2013). Children learning to read later catch up to children reading earlier. Early Childhood Research Quarterly, 28(1) 33-48.

Suggate, S., \& Stoeger, H. (2014). Do nimble hands make for nimble lexicons? Fine motor skills predict vocabulary of embodied vocabulary items. First Language, 34(3), 244-261.

Suggate, S., Stoeger, H. \& Pufke, E. (2016). Relations between playing activities and fine motor development. Early Childhood Development and Care, 187, 1297-1310.

Verdine, B., Golinkoff, R., Hirsh-Pasek, K., \& Newcombe, N. (2014). Finding the missing piece: Blocks, puzzles, and shapes fuel school readiness. Trends in Neuroscience and Education, 3(1), 7-13.

Vygotsky. L.S. (1933/2002). Play and its role in the mental development of the child. Journal of Russian and East European Psychology, 5(3).

Vygotsky, L.S. (1978). Mind in society: The development of higher psychological processes. Cambridge, MA: Harvard University Press.

Walker, T. (2015, October 1). The joyful illiterate kindergarteners of Finland. The Atlantic Retrieved from https://www.theatlantic.com/education/archive/2015/10/the-joyful-illiteratekindergartners-of-finland/408325/

Weisberg, D., Hirsh-Pacek, K., \& Golinkoff, R. (2013). Guided play: Where curricular goals meet a playful pedagogy. Mind, Brain, and Education, 7(2), 104-112.

Wellsby, M., \& Pexman, P. (2014). Developing embodied cognition: Insights from children's concepts and language processing. Frontiers in Psychology, 5, 504.

Westervelt. E. (2015, February 12). Blocks, play, screen time and the infant mind. [Weblog post]. Retrieved from http://www.npr.org/blogs/ed/2015/02/12/385264747/q-a-blocks-play-screen-timeand-the-infant-mind 
Williams, H., Pfeiffer, K., O’Neill, J., Dowda, M., McIvor, K., Brown, W., \& Pate, R. (2008). Motor skill performance and physical activity in preschool children. Obesity, 16, 1421-1426.

Wilson, F. (1998). The hand: How its use shapes the brain, language, and human culture. New York, NY: Pantheon Books.

Wilson, F. (1999, October). The real meaning of hands-on education. Waldorf Research Bulletin, 2-12. Retrieved from http://pyrites.org/publications_files/Hands\%20on\%20Education.pdf

Wolery, M., \& Bredekamp, S. (1994). Developmentally appropriate practices and young children with disabilities: Contextual issues in the discussion. Journal of Early

Intervention, 18(4), 331-341.

Author Biographies

Hetty Roessingh teaches in both the undergraduate and graduate programs at Werklund School of Education with the University of Calgary. Her research interests include longitudinal studies of language and literacy development in Grades 2-12.

Michelle Bence is passionate about early literacy development in the K-3 years. She has worked extensively with Alberta Education in early literacy assessment, including standard setting and validation studies and is a sought-after presenter at conferences and workshops. 